\title{
ПРЕДИКАЦИЯ В ЗЕРКАЛЕ УСИЛИТЕЛЬНЫХ ЧАСТИЦ
}

\author{
Е. Г. Борисова
}

Московский городской педагогический университет

\section{THE PHENOMENON OF PREDICATION AND MODAL PARTICLES}

\author{
E. G. Borisova \\ Moscow City University
}

\begin{abstract}
Аннотация: статья рассматривает понятие предикации как акта говорения с позиций лингвистики и прагматики. Для выявления особенностей средств передачи предикации используются свойства усилительных (модальных) частии, значения которых описываются с учетом общего значения лексемы. Рассматриваются преимущественно русские частицы. Отмечаются особенности фрагментов содержания, попадающие в сферу действия частии, на основании чего делаются выводы о наличии фрагментов значения в высказывании и их сходство или различия. В результате выявляются средства передачи предикации в речи, а также соотношение грамматических, синтаксических и функциональных (тема-рематических) способов приписывания свойств субъекту.
\end{abstract}

Ключевые слова: утверждение, пропозиция, речевой акт, глагол, рематизация, коммуникативный динамизм.

\begin{abstract}
: the article concerns the concept of predication that can be implemented in various units according to the levels of speech activity. The predication can be regarded - in the sphere of morphology as an immanent attribute of the Verb in personal form, (and the Adjective in some cases). In Syntax it is as a function of a Predicate. But besides that some features connected with the predication (uttering) can be proclaimed to be the principle property of a rheme (or comment). All these quants of sense of an utterance can enter into the scope of some modal (discourse) particles (the case of Russian is analyzed). More than 1200 examples of modal (emphasizing) Russian particles are taken into consideration and their principle meanings are denoted. As there is some difference in the usage of particles (some are used only with rhemes, some with predicates etc.) their comparison makes it possible to characterize the concepts in focus according to the similarity or differences in their combinations with particles. A hierarchy of the concepts concerning predication is offered: the Verb - the Predicate - the Modus (vs Dictum) - the Rheme (of the whole utterance and of some parts of it). The particles reveal the similarity of these concepts. Key words: utterance, proposition, speech act, verb, rhematisation, communicative dynamism.
\end{abstract}

\section{Введение. Предикация и предикативность}

Самая важная часть любой коммуникации предикация, т. е. акт передачи информации, что отмечено еще в античных грамматиках. И тем не менее споры о сути предикации, о соотношении предиката и глагола, предиката и ремы (или коммента) в актуальном членении продолжаются и в наши дни. В данной статье мы попробуем добавить к обширному множеству позиций по поводу этого явления и смежных с ним понятий те данные, которые получаются в результате учета места частиц (усилительных, или модальных) в семантике и прагматике высказывания.

Области знаний, которые в той или иной степени затрагивали проблему предикации, не ограничиваются языкознанием. Впервые [1] выделение «сказанного» произошло в античной философской традиции, где использовался термин «рема» (сказанное) и для предиката предложения, и для глагола. Оттуда же берет начало и термин «предикат», который, однако, уже разведен с термином «вербум», относящимся к глаголу.

(C) Борисова Е. Г., 2021 
В дальнейшем термин «предикат» использовался и в логике, и в философии, и в языкознании. В последнем русская традиция использовала кальку с древнегреческого «сказуемое», т. е. говоримое, сообщаемое. Русские грамматики достаточно четко разделяют глагол как часть речи и сказуемое как член предложения, который действительно обычно выражается личной формой глагола. Поскольку в русском языке (как, впрочем, и в некоторых других) в настоящем времени возможно именное сказуемое вообще без глагола (опущение глагола быль ), то это различие осознавалось всегда достаточно четко, хотя само это явление допускало и более унифицирующее толкование: «нулевая форма глагола быть в настоящем времени».

Тем не менее то, что «сказанное» может не совпадать со сказуемым, было понятно уже в конце девятнадщатого века, что проявилось во введении Бодуэном де Куртенэ понятий «психологическое подлежащее» и «психологическое сказуемое». В дальнейшем это нашло воплощение в теории актуального членения» [2-4].

И все-таки выделение ремы как «сказанного» не отменяет особого положения сказуемого, превращающего некоторый набор слов в сообщение (чаще всего утверждение, но также обращение, повеление, вопрос). Для описания особенностей этого действия в русской лингвистике было введено понятие «категория предикативности» [5], которая привязывала к акту предикации ряд грамматических категорий, выражаемых глаголом-сказуемым: время, модальность [6].

С предикацией связано и выделение так называемой «модальной рамки» высказывания, что в свою очередь является развитием оппозиции «диктум» и «модус» [7]. Это разделение содержания предложения на фрагмент смысла и его отношение к реальности, передаваемое в ходе высказывания, введено Ш. Балли. В модальную рамку принято выносить данные о цели акта говорения и другие его характеристики: отношение к реальности, время говорения и т. п.

Нелишне отметить, что поскольку само превращение некоторого содержания в реальное сообщение связано с речевой деятельностью, в этом аспекте можно рассматривать данное действие с прагматической точки зрения. В этой связи стоит обратить внимание на понятие «Речевой акт» в прагматике. Его использовали преимущественно для фиксирования различий в высказывании в зависимости от намерений говорящего. Однако в самом понятии «акт» уже выделяется действие как таковое. И в этом смысле можно провести определенные параллели с использованием междометий (особенно примитивных: одно-двухзвучных), произнесение которых - явно отдельный речевой акт со всеми признаками предика- ции. В то же время многие междометия имеют связи с так называемыми антропологическими звуковыми жестами, т. е. испусканием некоего звука, не находящего абсолютно точных соответствий в языке [8].

Таким образом, получается, что понятие предикации, т. е. действия говорящего по приписыванию каких-то свойств компонентам сообщения, относится исследователями к различным языковым уровням и структурам. Для того чтобы понять, насколько эти структуры представляют собой некое единство или хотя бы обладают сходством, а насколько можно и нужно учитывать различия между ними, следует обратиться к показаниям самого языка. Иными словами, для моделирования действия, которое исследователи называют предикацией [3-5], мы предлагаем обратиться к частицам: языковым единицам, которые одинаковым поведением сближают категории разных уровней, связанные с предикацией [9].

\section{Предикативность с позиций языка: материалы и методы исследования}

Целью исследования, описываемого в статье, является выявление особенностей предикативных действий в русском языке в соответствии с данными, демонстрируемыми поведением русских усилительных частиц. Материалом послужили фрагменты текстов с русскими усилительными частицами, собранными в период с 1977 г. по настоящее время (около 1200 употреблений частиц ЖЕ, ВЕДЬ, НУ, ДА, УЖ, -ТО, -ТАКИ, И, А, ВОТ), а также примеры из исследований, посвященных этой проблеме [10].

Использовался метод семантического анализа слова и конструкции, метод актуального членения, методы грамматического анализа, прагматический метод.

Для использования частиц как маркеров сходства и различия категорий важно иметь в виду их свойство сочетаемости с другими единицами. При описании сочетаемости используют понятие «сферы действия»-англ. Scope) [11; 12], которая может формулироваться как в терминах грамматики (когда в сферу действия попадают клауза, словосочетание, сказуемое), так и в лексических (слово с определенными свойствами) и в функционально-перспективном плане (тема, тема с особыми свойствами, рема, часть ступенчатой ремы и т. п.). Например, сферой действия частицы -ТАКИ может быть сказуемое: $O$ н-maки справился, рема (но не сказуемое) Он пришел-таки вечером, хотя некоторые ждали его позднее. В дальнейшем мы анализируем примеры, в которых в сферу действия частиц попадают единицы, так или иначе связанные с предикативностью: глаголы, сказуемые, рема. 
Употребление этих частиц демонстрирует определенные параллели в единицах разных функциональных сфер. Иными словами, при выявлении единиц разных уровней, связываемых с предикацией, мы учитываем объем сферы действия разных частиц: попадающие в эту сферу единицы должны учитываться как отдельные явления при описании. С другой стороны, сходство в поведении одной и той же частицы с разными единицами заставляет отражать его при описании данных единиц.

\section{Усилительные частицы и разные виды предикативности (Исследование)}

Рассмотрим частицы, которые могут относиться к предикации - к сказуемому в обычном предложении, и сравним эти употребления с другими, характерными для данной частицы.

1. Частица ЖЕ, имея общее значение «известность сообщения для слушающего» [13], чаще всего относится ко всему предложению, что позволяет включать в его сферу действия сказуемое:

(1) Я же тебе говорил.

Достаточно много примеров с повелительными:

(2) Закрой же дверь!

и вопросительными предложениями:

(3) Куда же я подевал ключи?

В вопросительных и повелительных предложениях в сферу действия тоже попадает предикация, Наконец, частица ЖЕ может относиться и к обращению:

(4) Вольха! Да Вольха же! (описывается ситуация, когда Вольху пытаются привести в сознание настоятельными обращениями).

Обращение не рассматривается как сказуемое, однако это тоже речевой акт, направленный на передачу информации, поэтому можно говорить, что высказывания-обращения тоже могут члениться на модус и диктум (т. е. на характеристику высказывания и на его содержание).

В то же время есть основания считать, что частица ЖЕ может включать в свою (семантическую) сферу действия и рему, в которую может и не входить предикат:

(5) Это же на завтра!

И усиление, и степень известности привязываются к наречию завтра. Несколько более сомнительно, но все еще допустимо:

(6) Tbl же в красном (т. е. пришла в красной одежде, что вызывает некоторые проблемы).

Заметим, что подразумеваемые предикаты (пришла, находишься) не относятся к семантической сфере, к фрагменту смысла, подлежащему усилению. Таким образом, частица ЖЕ включает в свою сферу действия сказуемое с зависящими членами, модус высказывания (в обращениях) и рему, не совпадающую со сказуемым.

2. Частица ВЕДЬ близка к частице ЖЕ по основному значению, хотя, видимо, степень известности здесь существенно меньше. Скорее можно описать общее значение ВЕДЬ как «говорящий полагает, что слушающий соглашается»:

(7) $\mathrm{Mbl} \mathrm{ведь} \mathrm{друзья,} \mathrm{правда?}$

Частица относится к сказуемому (в том числе и в нулевой форме, как в примере 7), однако только в предложениях утверждения и вопроса: другие модусы (повеление, обращение) в сферу действия частицы ВЕДЬ попасть не могут, ср. ?Открой ведь. В случае с вопросом он должен быть общим, примеры с частным вопросом возможны, если в сферу действия попадает другой смысл, например, импликатура:

(8) Ведь куда ты пошел? Выпивать!

Сравнение с частицей ЖЕ, допускающей гораздо более широкое сочетание с различными наклонениями, заставляет предположить, что для ВЕДЬ в сферу действия попадает не модальная рамка, включающая смыслы, связанные с наклонениями, а собственно предикация: утверждение о факте.

3. Частица ДА имеет несколько значений, которые могут быть выведены из фрагмента смысла, приблизительно описываемого как «говорящий удивлен, что собеседник нечто говорит». В некоторых случаях это удивление может показывать неоспоримость и интерпретироваться как «Странно, что ты сам не понимаешь»:

(9) Да это же очевидно!

(10) Да зачем тебе это?

(11) Да открой, наконец!!

Другая часть примеров скорее передает ослабленное значение:

(12) Да мы особо и не настаиваем, делайте, как xотите,

что может быть связано с удивлением, что нечто вообще стало предметом говорения, хотя оно того не заслуживает.

В этих значениях в сферу действия попадает модус предикации (утверждения), в том числе повеления - как настойчивого (11), так и снисходительного разрешения:

(13) Да сделай уже им, пусть отвяжутся.

В усилительном значении возможно попадание в сферу действия и обращения, см. пример (4). В значении «снисходительности» такое невозможно.

Встречаются и случаи, когда в семантическую сферу действия частицы попадает рема, не включающая сказуемого:

(14) Ну что говорить с замом? Да с директором, с директором поговорил бы!

Сходные возможности имеются и у частицы НУ: (15) Ну открой наконеи!! 
(16) Ну иди, если хочешь.

(17) Ну это неоспоримо!

(18) Ну Саня, ну же, просыпайся!

В целом обе частицы (несмотря на разное исходное значение и, насколько можно проследить, этимологию) способны придавать оттенки подчеркивания и, в некоторых случаях, ослабления речевого действия: утверждения, повеления, вопроса и даже обращения. Это осуществляется в результате взаимодействия значения этих частиц с попавшими в их сферу действия фрагментами значения «ремности» (факта сообщения), которые чаще всего совмещаются со свойством «быть сказуемым».

4. Ряд частиц скорее связаны с темой высказываний: ВОТ, УЖ, -ТО. Однако и в этом случае возможны параллели с употреблениями, связанными с предикацией. Рассмотрим частицу -ТО. Она употребляется тогда, когда тема, находящаяся в ее сфере действия, получает дополнительную информационную нагрузку [10]:

(19) А Иван-то женился!

Внимание к теме сообщения усиливается из-за внезапности обращения.

Аналогичное усиление значимости темы можно наблюдать при противопоставлении:

(20) Работает-то он хорошо, а вот дома... при уступке:

(21) Съесть-то он съест, да кто ж ему даст! и т. П.

Наконец, именно сдвиг внимания к теме оправдывает появление частицы -ТО во фразах с частицей И:

(22) Обсуждали летний отдых. Кто-то предложил Юрмалу. Туда-то мы и поехали.

В этом высказывании новая информация (ответ на вопрос «Куда решили ехать?») содержится в слове Tyда. Вместе с тем по правилам выбора темы (повторение фрагмента из предыдущего высказывания), это наречие должно стать темой. Частица -ТО позволяет разрешить это противоречие, маркируя тему, в чем-то связанную с ремой. (О роли частицы И будет сказано ниже.)

Частица ВОТ может маркировать и даже выделять тему [14]:

(23) Вот об этом поговорим поподробнее, и в то же время маркировать известность сообщения:

(24) Вас не удивила тема нашей встречи. Мы уже неоднократно подчеркивали важность этой проблемы, как она требует обсуждения... Имы вот обсуждаем здесь это.

Здесь ВОТ используется для маркировки связи события «обсуждаем» (перформатив, описывающий происходящее) с известной ситуацией или упомянутой ранее информацией. Иначе говоря, так маркируется неновизна и связь с описываемым событием [14].
В целом можно утверждать, что частица ВОТ (мы имеем в виду ее усилительный вариант) способна указывать на известность как информации в теме, так и в реме в предикативной части сообщения.

5. Частица УЖ может употребляться как с предикатами, так и с именами. При употреблении со сказуемыми в ее сферу действия попадает содержание события (диктум), а не предикация:

(25) Уж работал он добросовестно.

В этом смысле интересна также частица -ТАКИ: в ее сферу действия может попадать как рема (чаще всего совпадающая с предикатом), так и модус:

(26) Он-таки тянул время, а не реально не справлялся, как пытался всех убедить.

Здесь то, что он что-то делал, не вызывает сомнений, в отличие, к примеру, от:

(27) Ну вот, директор-таки уволился, как ни держался за место.

В (27) часть смысла, входящая в сферу действия частицы, это «факт имел место», хотя ранее в этом были сомнения, т. е. модус сообщения. А в (26) в сферу действия попадает не факт, а его характеристика (диктум): он что-то делал, но каково содержание действий, было неочевидно. Эта характеристика аналогичная сведениям непредикативного характера, попавшим в сферу действия -ТАКИ в примере:

(28) А разговаривал он-таки с новым директором: потом нам его представили, и я узнал тогдашнего собеседника.

Частица -ТАКИ способна включать в сферу действия как значение предикации «действие имело место» (пример 27), так и значение диктума: какое именно действие произошло (26). При этом в обоих случаях сфера действия совпадает с ремой высказывания.

6. Особое внимание следует уделить частице И. Ее происхождение от сочинительного союза, используемого для добавления информации (аналогичной предыдущей или выводимой из нее), четко просматривается в ряде случаев. Например, только позиция в предложении мешает отнести употребление со значением следствия:

(29) Мне приказали - я и пошел,

от союза (хотя некоторые смысловые отличия просматриваются при сравнении с обычным союзным употреблением: Мне приказали, и я пошел).

Имеются и более очевидные «частичечные» употребления в повествовательных предложениях, например, частица И в вопросах делает их риторическими, но это заслуживает отдельного рассмотрения. Одной из наиболее заметных является функция частицы И как средства изменения информационной и тема-рематической структуры. Для примеров типа:

(30) Надо работать - А я что делаю? Я и работаю, 
добавлением информации оказывается присоединение информации «на самом деле», т. е. фрагмент значения предикации. Интересно посмотреть, что в ряде случаев это добавление требует выражения предикации в явном виде:

(31) Позови старшего - А я и есть старший.

Здесь опускаемый обычно глагол-связка должен быть употреблен. В этом смысле интересно посмотреть на предикационный потенциал прилагательных. Если с полными прилагательными добавление связки обязательно, см. (31), а также:

(32) Я просил принести красный! - Это и есть красныцй,

то с краткими есть не добавляется:

(33) Мне бы нужен опытный специалист. - Он и опьтен!

В этом смысле краткие прилагательные оказываются такими же носителями предикативности, как и глаголы в личной форме. Близкими к ним оказываются причастия, которые могут входить в данную конструкцию и со связкой, и без нее:

(34) А работающего устройства нет? - Оно и (есть) работающее!

Понятно, что добавляемый в таких случаях небольшой фрагмент информации соответствует и реме высказывания. Несколько иную роль частица И может играть и относительно ремы, которая не сводится к столь узкому фрагменту смысла, как чистая предикация: (ср. пример (22)).

Здесь частица И показывает, что сообщаемое в предикативной части (и в рематической) не содержит нового, а содержит уже упомянутое, или подразумеваемое, или известное всем заранее:

(35) В результате это решение и воплощчали большевики в первые годы своего правления.

Таким образом, частица И включает в свою сферу действия рему, но при этом не включает новизну.

\section{Предикация и сходство в поведении частиц. Результаты исследования}

Таким образом, мы видим, что одни и те же частицы могут включать в свою сферу действия элементы, относящиеся к разным языковым и речевым структурам: к организации семантики высказывания (модус -ТАКИ, диктум УЖ), информационной структуре (новое, привлечение внимания -ТО), функциональной структуре (тема -ТО, рема ЖЕ, ДА и др.), синтаксической структуре (сказуемое, частица И). В некоторых случаях играет роль и морфологическая характеристика (глагол, краткое прилагательное, частица И). Если исходить из того, что при этом частица имеет одно и то же (или хотя бы сильно схожее) значение, описывая его, мы отмечаем сходство этих структур. Таким образом, мы получаем шанс прояс- нить ситуацию с языковой природой явлений, так или иначе связанных с предикацией.

Большая часть частиц, относящихся к содержанию высказывания, имеют сферой действия рему сообщения (главную рему, если пользоваться моделью коммуникативного динамизма Я. Фирбаса [15]). Это частицы ЖЕ, ВЕДЬ, ДА, НУ, -ТАКИ. Поскольку для этих частиц выделяется такой компонент значения, как «содержание представляется несомненным», можно утверждать, что именно это значение связано с основным содержанием высказывания.

Однако в сферу действия рематических частиц попадают и компоненты, связанные с актом предикации. Это видно по тому, что данные частицы ведут себя по-разному в отношении некоторых видов утверждений. Так, при сходстве поведения в утвердительных предложениях частицы ЖЕ и ВЕДЬ по-разному ведут себя с обращениями: обращение с ЖЕ возможно, хотя и не очень часто (см. пример (4)), с ВЕДЬ нам не встретилось. Может использоваться с обращением частица НУ, причем почти без ограничений:

\section{(36) Ну товарищ генерал!}

Частица ДА с обращением используется, но практически все найденные случаи включают одновременное использование и частицы ЖЕ. Сочетания обращения с другими частицами, кроме перечисленных, практически отсутствуют. Некоторые носители признают возможным сочетание обращения с частицеЙ -ТАКИ:

(37) Маша! Давай сюда! Что, другие? Есть другие? Нет. Маша-таки!,

однако оно явно на грани допустимого. Таким образом, для частиц ВЕДЬ и, до определенной степени, -ТАКИ важно, чтобы в сферу действия попадал смысл, связанный именно с предикацией как синтаксическим явлением, который присутствует в утвердительных предложениях, но отсутствует в обращениях, а возможно и в повелении, и в вопросах (ср. разбор примеров 7 и 8).

Поскольку обращение - это речевой акт, схожий с предикацией, осуществляемой сказуемым, но не совпадающий с ним, можно говорить, что частицы позволяют выделить единицу, соответствующую акту предицирования, наблюдаемому и в обращении, и в сказуемом. Можно связать этот смысл с модусом высказывания, куда, помимо значения речевого акта «я говорю», попадают и другие значения. А поскольку все обозначенные частицы используются с ремой, то аналогичную единицу можно связать и с ремой высказывания.

Некоторые частицы одинаково «работают» и с предикативными элементами, и с номинативными. Так частица ВОТ может маркировать и даже выделять тему: 
(38) Вот об этом поговорим поподробнее, и в то же время маркировать известность сообщения:

(39) Вас не удивила тема нашей встречи... И мы вот обсуждаем здесь это.

Здесь ВОТ используется для маркировки связи события «обсуждаем» с известной ситуацией или упомянутой ранее информацией. Иначе говоря, так маркируется неновизна и связь с описываемым событием [10]. В целом можно утверждать, что частица ВОT (мы имеем в виду ее усилительный вариант) способна указывать на известность как информации в теме, так и в реме, в предикативной части сообщения.

Особый интерес в связи с соотношением разных языковых структур, связанных с предикацией, представляет частица И, которая, имея сферой действия рему, употребляется только со сказуемыми, а (в другом значении) имея сферой действия утверждение свойство предикации - требует употребления с глаголом даже тогда, когда по законам русского языка сказуемое образуется именем и глагол-связка может опускаться.

Параллелизм в употреблении некоторых частиц с единицами разных языковых и речевых структур заставляют обратиться к моделям речевого поведения, описывающим роль усилительных частиц в речевой деятельности, в частности, связанных с управлением слушающим в части понимания сообщения [10]. Поскольку языковые структуры так или иначе служат для обеспечения понимания, роль специальных единиц становится важной тогда, когда эти структуры могут не полностью обеспечить понимание.

Опираясь на уровневую модель языка и функции частиц, можно выстроить следующую модель понимания сообщения. Адресат ориентируется на морфологический уровень, где выявляет структуры (глагол, глагол-связка, прилагательное в краткой форме), которые ожидаемо должны выступать в роли сказуемого - структурного носителя предикации, а вместе с ней - основного сообщения (информации).

Тема-рематическая структура использует различные средства для указания слушателю, что именно является содержанием сообщения. Это становится важно, когда ожидание относительно структурной формы носителя предикации - сказуемого - нарушается. Иногда содержание распределяется равномерно по всему высказыванию (Коммуникативный динамизм Я. Фирбаса). А иногда (эмфаза) концентрируется на отдельных фрагментах смысла, в том числе на модусе высказывания (ср. пример (30)). В этих случаях используются частицы, маркирующие эмфазу (что и позволяет называть их усилительными, хотя их функции в целом более разнообразны).

Некоторые особые случаи (обращение, повеление) демонстрируют важность для коммуникации элемента смысла, который можно назвать содержанием самого речевого акта (возможно, его следовало бы назвать предикацией), который присутствует и в других утверждениях, хотя и не всегда может оказаться в сфере действия некоторых частиц. В существующих моделях данный смысл можно отождествить с одним из компонентов модуса (модальной рамки).

\section{Заключение (Выводы)}

Для выяснения природы предикации, т. е. акта речевого действия (утверждения или отрицания, вопроса, требования и обращения), были рассмотрены особенности употребления ряда усилительных частиц, которые способны влиять на передачу информации, при этом относясь к какой-либо части сообщения. Выделение этих частей является доказательством существования фрагментов смысла, соответствующим речевым структурам разного уровня, а аналогичность, а иногда и совпадение механизмов частиц, показывают сходство и взаимную связь таких структур.

Результаты рассмотрения заявленных выше усилительных частиц показали, что основным содержимым сферы действия оказываются элементы актуального членения: рема (главная рема по Я. Фирбасу), тема, имеющая некоторые особенности ремы (контрастная, содержащая новое). Ряд частиц способны взаимодействовать и с ремой, и с единицами других уровней: И, ВОТ, -ТАКИ. Так, частица И взаимодействует и с носителем предикативности (глагол в личной форме, краткое прилагательное), и с ремой (обычно выраженной тем же глаголом). Частица ВОТ чаще всего образует сферу действия с именем, которое играет роль темы в высказывании. Но может относиться и к предикативной части, в том числе и рематической. Главное условие здесь - известность содержания (диктума) сообщения.

В целом можно признать, что наблюдения над поведением усилительных частиц, в первую очередь над содержанием их сфер действия, позволяют сделать определенные выводы о языковых структурах, обеспечивающих подачу информации в коммуникации.

В целом получается, что вокруг действия предикации выстраиваются следующие системы понятий.

Глагол (личная форма), которую можно рассматривать в зеркале «изоморфизма частей речи, т. е. как средство отражения особенных смысловых комплексов: действия, состояния, явления, процесса). Близкие функции обнаруживаются у такой уходящей формы, как краткое прилагательное, которое не требует - в отличие от полного прилагательного и имен существительных - дополнительных морфологических средств предикативизации (прояснения глагла-связки быть в некоторых контекстах). 
Сказуемое как главный (в русской традиции один из двух главных) членов предложения. Именно с ним связана категория предикативности.

Модус высказывания (в оппозиции модус-диктум) или модальная рамка.

Рема как часть содержания высказывания, берущая на себя некоторые функции предикации (сообщаемое содержание), но не отменяющая привязку предикации к сказуемому. Реальное построение высказываний обычно заставляет представлять рему как ступенчатую конструкцию, в которой начало ремы (при нейтральном порядке слов) в то же время может быть распространено следующим утверждением. Это явление можно описать как степень рематичности или как коммуникативный динамизм (понятие введено Я. Фирбасом [2].

Имеется явный параллелизм между ремой и действием - речевым актом - проявляющим себя в обращении (и возможно, в других периферийных явлениях типа междометных высказываний, которые нами не рассматривались).

Наконец, приходится принимать во внимание еще и понятие «Новое как цель сообщения». При этом новизна может пониматься в чисто информационном смысле. Ожидание новизны связывается с ремой, которая и предназначена для выражения нового, поскольку именно для этого обычно и делаются утверждения. Нарушение ожидания маркируется частицами - отсутствие новизны в реме (частицы И, ЖЕ) или ее присутствие в теме (частицы -ТО, ВОТ).

Перед нами несколько уровней языковой структуры, единицы которых используются для передачи новой информации, и признаки которых сигнализируют адресату о том, что является передаваемым. В тех случаях, когда эти ожидания надо корректировать: реальная ситуация общения отличается от типовой - используются усилительные частицы. Поэтому описание частиц привязано к элементам структуры. Обращение к частицам позволяет подтвердить наличие значения этих структур в содержании сообщения. А поскольку каждая частица имеет определенное единство семантики, то возможность использования одной и той же частицы с единицами разных уровней (как частица И с глаголом и сказуемым, -ТАКИ с модусом и ремой) показывает на сходство важнейших черт этих единиц.

В ряде языков отдельные ступени приведенной выше лестницы оказываются не нужны или невозможны: в китайском не выделяются такие единицы, как глагол, в то же время предикаты могут оказаться частью определения. Для английского разделение глагола и сказуемого не столь актуально (в порождающих грамматиках оно последовательно не проводится). Кроме того, во многих языках имеются формы, именные по морфологическим характеристикам, однако имеющие возможность сообщать о каких-либо событиях. Это причастия и деепричастия, герундий, некоторые породы в арабском и т. п. В русской традиции данное явление называется «полупредикативностью», что вводит понятие степени предикативности непосредственно в грамматику.

\section{ЛИТЕРАТУРА}

1. Соловьева О. Н. Предикативный потенциал двусоставных предложений : дис. ... канд. филол. наук. Оренбург, 2015.

2. Беклемешева Н. Н. Интерпретация вторично-предикативных структур в перспективе актуального членения : дис. ... канд. филол. наук. М., 2008.

3. Николаева T. Г. Критический анализ понятий «предикация» и «предикативность» в современной лингвистике // Известия Волгоград. гос. пед. ун-та. 2018. № 4 (127). C. 82-87.

4. Ryukova A. P. Functional Sentence Perspective // Вестник Башкир. ун-та. 2018. Т. 23, № 4. С. 1173-1175.

5. Дымарский М. Я. Способы воплощения предикативного отношения // Acta Linguistica Petropolitana: труды Института лингвистических исследований РАН. T. ХІ, ч. 1. Категории имени и глагола в системе функциональной грамматики / М. Д. Воейкова [и др.]. СПб. : Наука, 2015. С. 45-68.

6. Костюченко В. Ю. Категория модальности с точки зрения логики и лингвистики : сходства, различия и перспективы синтеза // Журнал Белорус. гос. ун-та. Филология. 2018. № 3. С. 71-82.

7. Балли Ш. Общая лингвистика и вопросы французского языка. М. : Едиториал УРСС, 2001. 416 с.

8. Ameka F. Interjections : The universal yet neglected part of speech // Journal of Pragmatics. 1992. № 18. Pp. 101-118.

9. Курдюмов В. А. Предикация и природа коммуникации : автореф. дис. ... д-ра филол. наук. М., 1999. 39 с.

10. Борисова Е. Г. Управление пониманием. Языковые единицы, регулирующие понимание сообщения // Вестник Моск. ун-та. Сер. 9, Филология. 2018. № 6. C. 34-50.

11. Богуславский И. М. Сфера действия лексических единиц. М. : ЯРК, 1996. 468 с.

12. Fraser B. An approach to discourse markers // Journal of Pragmatics. 1990. № 14. C. 383-395.

13. Храковский В. С., Володин А. И. Опыт анализа семантико-синтаксических свойств усилительной частицы же (ж) в императивных конструкциях // Семантика служебных слов / под ред. Ю. А. Левицкого. Пермь : ПермГУ, 1982. С. 23-33.

14. Борисова Е. Г. Принципы описания служебных слов // Вестник Моск. гос. ун-та. Сер. Филология 1999. № 3. С. 71-86.

15. Пономаренко E. В. Функциональная перспектива дискурса как объект лингвистики и лингводидактики // Лингвострановедение : методы анализа, технология обучения : двенадцатый межвуз. семинар по лингвостра- 
новедению (Москва, 9-10 июня 2014) : сб. ст. : в 2 ч. Ч. І. Языки в аспекте лингвостановедения / отв. ред. Л. Г. Веденина. М. : МГИМО-Университет, 2015. С. 36-47.

\section{REFERENCES}

1. Solovyeva O. N. Predikativnyy potentsial dvusostavnykh predlozheniy. Diss...kand. filol. nauk. Orenburg, 2015.

2. Beklemesheva N. N. Interpretatsiya vtorichno-predikativnykh struktur v perspektive aktualnogo chleneniya. Diss. kand. filolog. nauk. M., 2008.

3. Nikolayeva T. G. Kriticheskiy analiz ponyatiy «predikatsiya» $\mathrm{i}$ «predikativnost» v sovremennoy lingvistike. In: Izvestiya Volgogradskogo gosudarstvennogo pedagogicheskogo universiteta. 2018. No. 4 (127). Pp. 82-87.

4. Ryukova A. P. Functional Sentence Perspective. In: Vestnik Bashkir. un-ta. 2018. T. 23, No. 4. Pp. 1173-1175.

5. Dymarskii M. IA. Predikatsiia i predikativnost philology ru

6. Kostiuchenko V. U. Kategoriia modalnosti s tochki zreniia logiki i lingvistiki skhodstva razlichiia i perspektivy sinteza. In: ZHurnal Belorusskogo gosudarstvennogo universiteta. Filologiia. 2018. No. 3. Pp. 71-82.

7. Balli SH. Obshchaia lingvistika i voprosy frantsuzskogo iazyka. M. : Editorial URSS, 2001. 416 p.

Московский городской педагогический университет

Борисова Е. Г., профессор Института иностранных языков

E-mail: borisovaeg@mgpu.ru

Поступила в редакцию 17 апреля 2021 г.

Принята к публикаџии 15 июня 2021 г.

\section{Для цитирования:}

Борисова Е. Г. Предикация в зеркале усилительных частиц // Вестник Воронежского государственного университета. Серия: Лингвистика и межкультурная коммуникация. 2021. № 3. C. 22-29. DOI: https://doi. org/10.17308/lic.2021.3/3575
8. Ameka F. Interjections: The universal yet neglected part of speech. In: Journal of Pragmatics. 1992. No. 18. Pp. 101-118.

9. Kurdiumov V. A. Predikatsiia i priroda kommunikatsii: avtoref dis d-ra filolog nauk. M., 1999.

10. Borisova E. G. Upravlenie ponimaniem IAzykovye edinitsy reguliruiushchie ponimanie soobshcheniia. In: Vestnik Moskovskogo universiteta Ser 9 Filologiia. 2018. No. 6. Pp. 34-50.

11. Boguslavskii I. M. Sfera deistviia leksicheskikh edinits. M.: IARK, 1996. 468 p.

12. Fraser B. An approach to discourse markers. In: Journal of Pragmatics. 1990. No. 14 . Pp. 383-395.

13. KHrakovskii V. S., Volodin A. I. Opyt analiza semantiko-sintaksicheskikh svoistv usilitelnoi chastitsy zhe zh v imperativnykh konstruktsiiakh. In: Semantika sluzhebnykh slov, pod red. Yu. A. Levitskogo. Perm: PermGU, 1982. Pp. 23-33.

14. Borisova E. G. Printsipy opisaniia sluzhebnykh slov. In: Vestnik MGU. Ser. Filologiia 1999. No. 3. Pp. 71-86.

15. Ponomarenko E. V. Funktsionalnaia perspektiva diskursa kak obieekt lingvistiki i lingvodidaktiki. In: Lingvostranovedenie: metody analiza, tekhnologiia obucheniia Dvenadtsatyi mezhvuzovskii seminar po lingvostranovedeniiu (Moskva 9-10 iiunia 2014): Sb. statei: v 2 ch. Ch. I. IAzyki v aspekte lingvostanovedeniia. Otv. red. L. G. Vedenina. M.: MGIMO-Universitet, 2015. Pp. 36-47.

Moscow City University

Borisova E. G., Professor of the Institute for Foreign Languages

E-mail:borisovaeg@mgpu.ru

Received: 17 April 2021

Accepted: 15 June 2021

\section{For citation:}

Borisova E. G. The phenomenon of predication and modal particles. Proceedings of Voronezh State University. Series: Linguistics and Intercultural Communication. 2021. No. 3. Pp. 22-29. DOI: https://doi.org/10.17308/lic.2021.3/ 3575 